\title{
Distributional impacts of carbon pricing in developing Asia
}

\author{
Jan C. Steckel ${ }^{1 凶}$, Ira I. Dorband ${ }^{1,2}$, Lorenzo Montrone ${ }^{1,2}$, Hauke Ward ${ }^{1,3}$, Leonard Missbach ${ }^{1,2}$, \\ Fabian Hafner', Michael Jakob (1) ${ }^{1}$ and Sebastian Renner ${ }^{1,4}$
}

\begin{abstract}
Understanding who would be affected in which way by carbon pricing is pivotal for effective and socially equitable policy design, addressing climate change and reducing inequality. This paper focuses on eight key countries in developing Asia (Bangladesh, India, Indonesia, Pakistan, Philippines, Thailand, Turkey and Vietnam). By combining national household surveys with inputoutput data, we compare the distributional effects of four carbon pricing design options, including a globally harmonized carbon price, a national carbon price and sectoral carbon prices in the power and transport sectors, respectively. Our analysis reveals a substantial degree of variation regarding who would be affected across policy designs and countries. Looking into national carbon pricing as the most favourable policy option from an economic point of view, we find that differences in distributional outcomes are generally more pronounced within income groups than across income groups. These differences are mainly driven by households' energy use patterns, which vary across countries. Equally recycling revenues back to all citizens would overcompensate the burden of a carbon price for the poorest households in all countries.
\end{abstract}

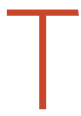
achieve the Paris goals, climate policies will increasingly need to be implemented in low- and middle-income countries. A growing number of countries consider carbon pricing as a means to achieve their emissions targets, including in Asia ${ }^{1}$. The region is important with respect to global climate mitigation efforts as its high energy demand growth has mainly been fuelled by carbon-intensive coal in recent years. Across the globe, >500 GW of coal power is currently under construction or planned ${ }^{2}$, most of it (>89\%), located in developing Asia. Once built the planned coal capacity would seriously jeopardize the Paris climate targets ${ }^{3,4}$. Even though it is too early to know how COVID-19 will affect further investment plans, investments in coal can be expected to continue if recovery packages are not increasingly targeted at green investments ${ }^{5,6}$.

Economy-wide carbon pricing is generally seen as the economically most efficient policy to reduce greenhouse gas emissions? ${ }^{7}$. A sufficiently high carbon price would substantially reduce incentives to invest in new coal-fired power plants and could make clean forms of electricity generation, such as renewables, economically competitive. Public support for carbon pricing depends on its distributional effect, that is which parts of the population are affected in which way by the policy. Therefore, policies that directly increase the prices of fossil fuels can be contentious, as demonstrated by protests in France in late 2018 (after an increase of carbon taxes on fuels) as well as in Ecuador in late 2019 (following proposals by the government to cut fossil fuel subsidies).

In this paper, we contribute to the understanding of distributional implications of carbon pricing in eight Asian countries which are among those that currently invest most heavily in coal, namely Bangladesh, India, Indonesia, Pakistan, Philippines, Thailand, Turkey and Vietnam. They host $16 \%$ of the current global coal capacity and $37 \%$ of the global coal pipeline $(73 \%$ of the pipeline outside China); that is, what is currently under construction and planned (Extended Data Table 1). It is hence highly unlikely that international climate policy will succeed without those countries undertaking efforts to reduce their emissions and avoid future lock-ins.

At the same time, these countries face substantial challenges to promote human development objectives in line with the agenda of the Sustainable Development Goals (SDGs). Some previous studies have analysed the relationship between climate change mitigation (SDG13) and socio-economic development, in particular energy access (SDG7) ${ }^{9}$ and the health benefits of reducing ambient air pollution due to fossil fuel combustion (SDG3) ${ }^{10}$. Our study, by contrast, focuses on the distribution of income (SDG10) in a cross-country perspective on the basis of detailed accounts of household carbon footprints derived on the basis of a unified methodology. It hence differs from previous studies that have either looked at individual countries ${ }^{11}$ or used a cross-country approach based on highly aggregated data ${ }^{12}$. Some comparable analyses have been undertaken for Latin America ${ }^{13}$ as well as the $\mathrm{EU}^{14}$ but to our knowledge not for Asia. Our paper extends the geographical coverage and provides a detailed analysis of horizontal equity and the distributional effect of different approaches to carbon pricing that were hitherto restricted to single-country studies ${ }^{15,16}$.

Our analyses answer three questions. First, we compare the distributional impacts of different design options for carbon pricing, including an international harmonized carbon price, national economy-wide carbon pricing as well as sectoral carbon prices that only apply to the electricity or transport sector, respectively. Second, we compare the vertical and horizontal distributional effects (across and within income groups) of a national carbon price of US $\$ 40$ per $\mathrm{tCO}_{2}$ (which is regarded as the lower bound required to achieve the targets of the Paris Agreement ${ }^{17}$ ). Note that we focus on a national carbon price as the most efficient option from an economic theory point of view. Third, we analyse why the distributional incidences of national carbon prices differ across countries as a result of differences in spending patterns for different consumption categories.

'Mercator Research Institute on Global Commons and Climate Change, Berlin, Germany. ${ }^{2}$ Department Economics of Climate Change, Technische Universität Berlin, Berlin, Germany. ${ }^{3}$ Department of Industrial Ecology, Institute of Environmental Sciences (CML), Leiden University, Leiden, the Netherlands. ${ }^{4}$ German Institute for Global and Area Studies (GIGA), Hamburg, Germany. ${ }^{凶}$ e-mail: steckel@mcc-berlin.net 

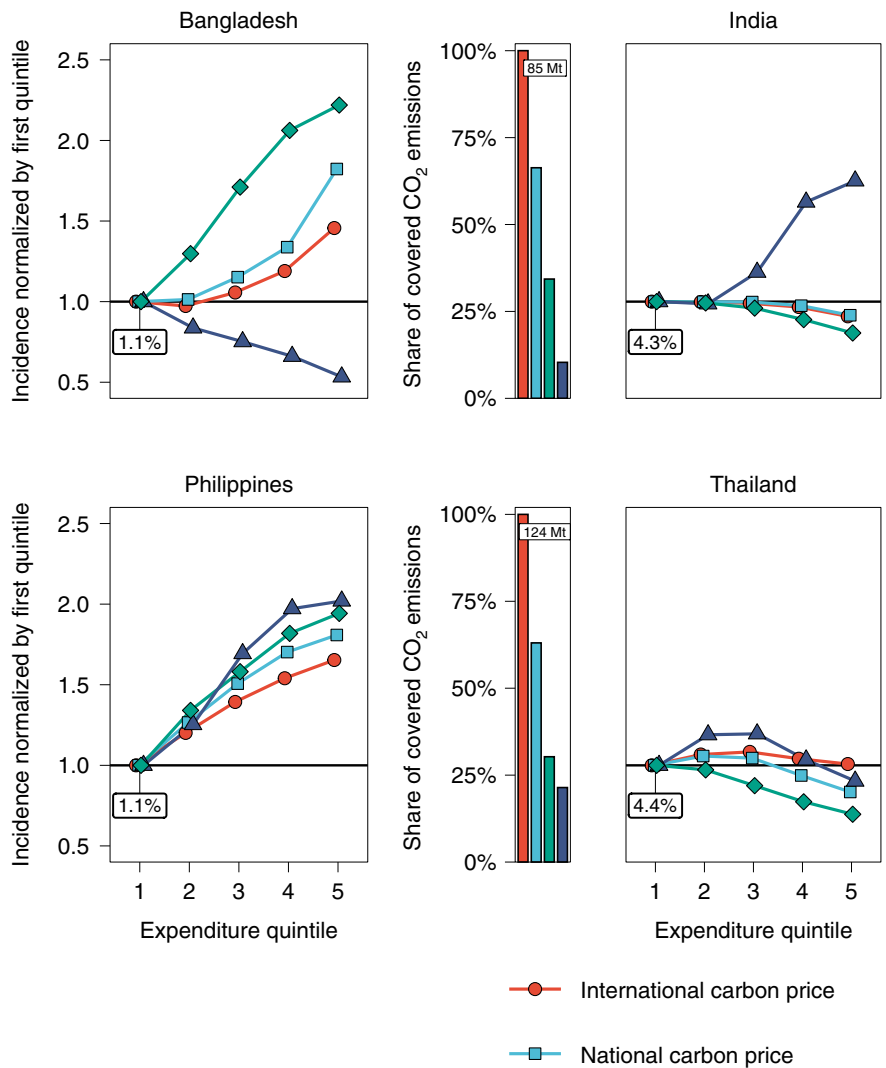
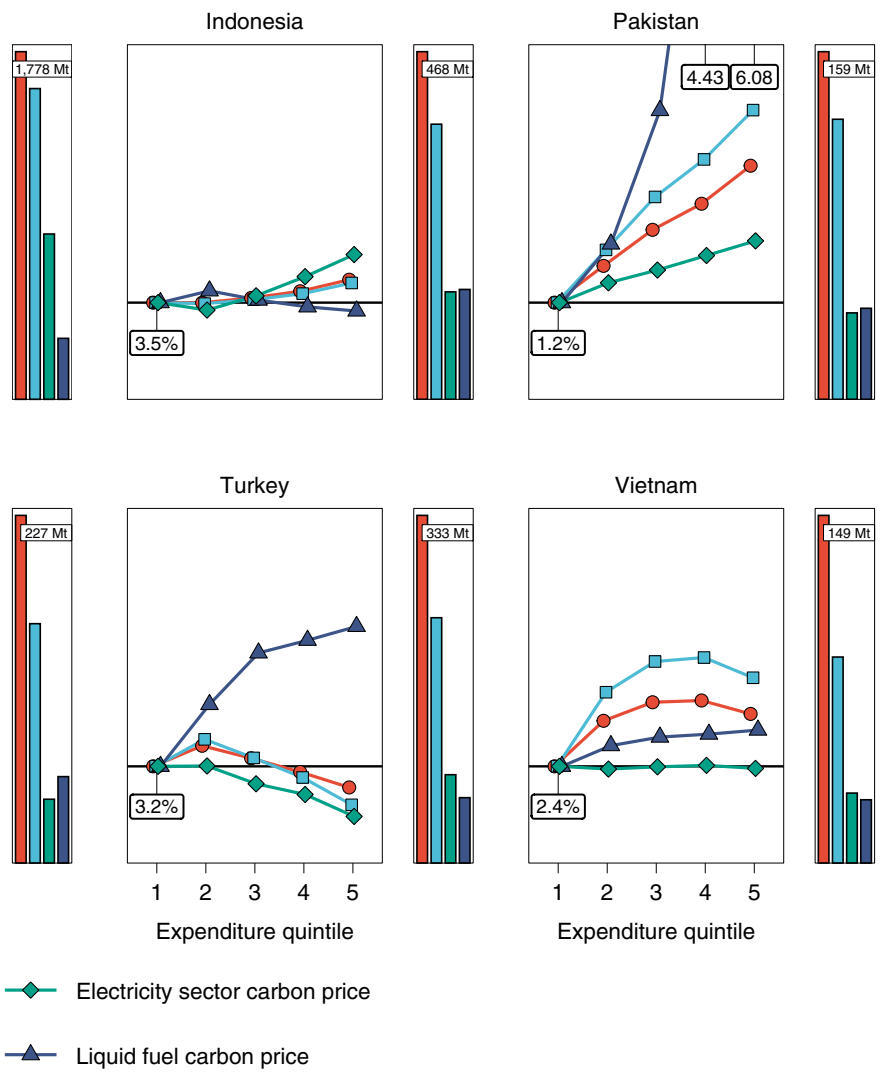

Fig. 1 | Relative median incidence of a national carbon price by quintile. Dots refer to the average incidence in each household quintile for: (1) a global carbon price (red), (2) a national carbon price (light blue), (3) an electricity sector carbon price (green), and (4) a liquid fuel carbon price (purple) normalized to the average incidence of the first quintile. A value of, for example, 1.2 would imply a $20 \%$ higher median effect on households of expenditure quintile $i$ relative to the median effect of the first expenditure quintile. Note that no revenue recycling is assumed (Fig. 5 and Supplementary Table 18 show the effects of revenue recycling). Label at first quintile shows the median incidence for a national carbon price (Supplementary Table 10). Bars display the amount of covered $\mathrm{CO}_{2}$ emissions for each instrument, expressed as a share of global emissions embedded in national consumption. Labels display total levels of global emissions embedded in national consumption.

There is a large literature on distributional implications of climate- and energy-policies across income groups, using different methods and datasets (see Ohlendorf et al. ${ }^{11}$ for a review). Previous studies have, for instance, assessed the distributional impacts of fuel taxes ${ }^{18}$, fossil fuel subsidy reform ${ }^{19}$ and carbon pricing ${ }^{12}$ from a cross-country perspective. Recent literature has also taken into account 'horizontal' distributional effects within income groups ${ }^{15,16}$. Our paper provides a cross-country, cross-instrument analysis with highly detailed and representative household data that examines distributional implications across as well as within income groups and sheds light on underlying drivers of variation.

To understand how different household types would be impacted, we perform microsimulations on the basis of representative household survey data and multiregional input-output (MRIO) data. Survey data are collected from the countries' statistical agencies, harmonized and matched with an environmentally extended MRIO model (Methods and Supplementary Information provide details). Combining both datasets allows us to identify the carbon footprint of households. To assess the distributional impacts of a carbon price, we derive the additional expenditure they would require to maintain their initial consumption. Throughout this analysis we proxy household income by expenditure ${ }^{20,21}$. Our analysis accounts for the effects of higher costs for direct energy use as well as rising prices for goods and services that use energy as inputs in their production (Supplementary Fig. 10 gives a decomposition of those effects). Despite some methodological limitations regarding the matching of household surveys to MRIO data and issues related to data availability, our results appear to be robust under a broad set of alternative specifications (Supplementary Information).

\section{Comparing different design options}

From a first best point of view, a globally homogenized carbon price would be economically optimal ${ }^{22}$. Arguably, given the political realities, this is unlikely to unfold anytime soon. Yet, some countries have proposed national economy-wide carbon pricing schemes or schemes that target specific sectors. In China, for example, the recently launched emission trading scheme is focusing on the power sector. We hence compare the distributional effects of four different design options for carbon pricing: an internationally harmonized carbon price, a national carbon price, a carbon price that focuses on the electricity sector and a carbon price on liquid fuels, covering mainly the transport sector. We assign households to quintiles on the basis of total per capita expenditures and normalize the median distributional incidences by quintile to the first one (the poorest $20 \%$ of the population) to make results comparable across countries and instruments. The shape of distributional incidences therefore is independent of the absolute magnitude-and hence of the level of the carbon price. Instead, it emphasizes whether richer households are more or less strongly affected than poor households (relative to their income).

Figure 1 reveals a large heterogeneity of distributional effects across countries and policies. Pakistan and the Philippines are the 

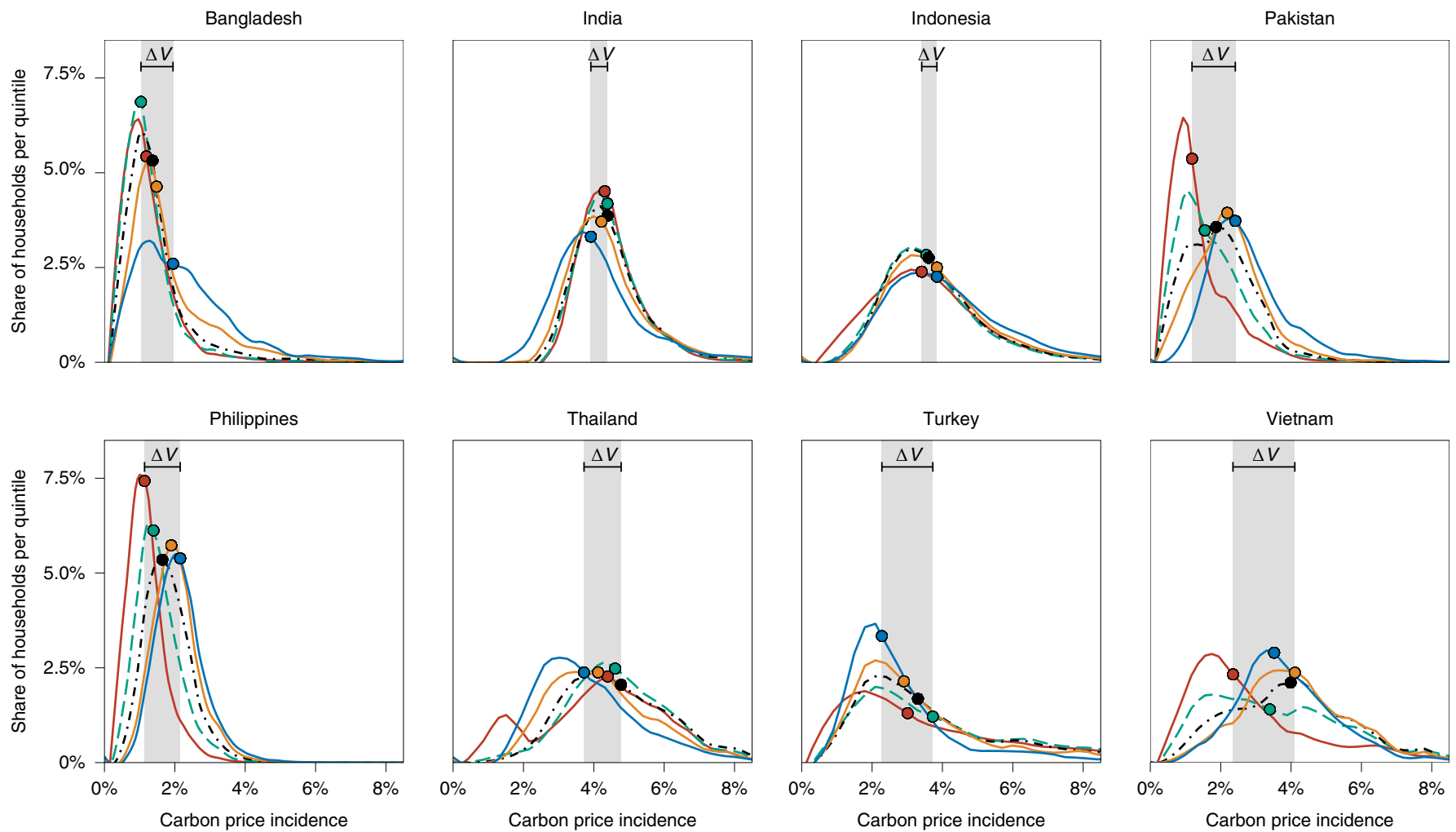

Expenditure quintile $\longrightarrow-1-0-2 \cdot \rightarrow-3 \multimap 0-4 \longrightarrow 5$

Fig. 2 Distribution of the incidence of a national carbon price by quintile. Each smoothed density curve refers to the distribution of cost burden as percentage of household expenditures for a US $\$ 40$ per $\mathrm{tCO}_{2}$ carbon price ( $x$ axis). The $y$ axis displays the share of households within each quintile. Curves are fitted over binned incidence levels with $\Delta x=0.1 \%$. Colours and line styles refer to expenditure quintiles and the dots correspond to median values in each quintile. Area in grey displays $\Delta V$, the difference in medians between the most- and least-affected expenditure quintile at the median (Table 1). When any given expenditure quintile is more affected, its curve is skewed more to the right. Households within expenditure quintiles are more heterogeneously affected, if curves are more widespread. Cumulative densities sum up to $100 \%$.

only two countries in which all designs would lead to progressive outcomes. In Bangladesh and Indonesia, all design options but carbon pricing only for liquid fuels would be progressive. Generally, a carbon price on liquid fuels seems to follow slightly different distributional patterns than other design options; also in Turkey and India (where it is the only progressive policy) and in Pakistan (where it is substantially more progressive than other policies). In Thailand, where most policies would be regressive, we find a hump-backed shape with the highest impacts on middle class households. A national economy-wide carbon price would be progressive in five countries, neutral in one and mixed or regressive in two (Thailand and Turkey). Hence, whether a certain policy is progressive or regressive, as well as the ranking of different policy instruments with regard to their distributional effects, depends on the specific country context.

The analysis in Fig. 1 also allows to measure differences between instruments in terms of their progressivity and the share of households' carbon footprints that would be covered. For example, while a tax on liquid fuels would be highly progressive in India, it would only cover $<20 \%$ of the country's emissions.

\section{Absolute effects of a national carbon price}

Arguably, it is also important how households are affected in absolute terms, which is particularly relevant when concerned about the political acceptability of a price reform. Absolute effects vary considerably between the poorest quintiles across countries. In Bangladesh, Pakistan and the Philippines, a US $\$ 40$ per $\mathrm{tCO}_{2}$ national carbon price would impact poorest households by $\sim 1 \%$; in India and Thailand, it would be $>4 \%$ of their expenditures.

Figure 2 zooms into the absolute effects of a national US $\$ 40$ carbon price. Note that Supplementary Tables 15-17 also indicate results for the other instruments discussed above, including international carbon price, transport sector carbon price and electricity sector carbon price. Due to the linearity of the input-output system, these effects can be generalized for different carbon prices by proportional scaling. Despite progressive or neutral distributional effects for most of the countries in the sample, the absolute effects of a carbon price of this magnitude would be substantial. Median values for the poorest quintile are identical to the values indicated in Fig. 1. For example, in India, poor households would need to increase their expenditures by on average $4.5 \%$ to maintain their current consumption patterns, while $25 \%$ of poor households would even be affected by $>5 \%$. The major driving factor for these large welfare impacts in India is the relatively carbon-intensive agricultural sector, mostly regarding the production of rice, wheat, grains, fruits and other crops (Supplementary Table 8), in combination with high expenditure shares for food by Indian households.

The distributions in Fig. 2 already indicate that the horizontal effect (within quintiles) is more disperse than the vertical effect between quintiles. Table 1 offers a detailed comparison of vertical and horizontal distributional effects. It compares the spread (in percentage points) between the most- and the least-affected quintile to each quintiles' spread between the 20th and the 80th percentile. Note that we also apply additional measures to quantify the 
Table 1 | Vertical and horizontal effects of a US $\$ 40$ national carbon price

\begin{tabular}{|c|c|c|c|c|c|c|c|c|c|c|}
\hline \multirow[b]{2}{*}{ Country } & \multicolumn{3}{|c|}{ Vertical effects } & \multicolumn{5}{|c|}{ Horizontal effects } & \multicolumn{2}{|c|}{ Comparison } \\
\hline & $Q_{\min }$ & $Q_{\max }$ & $\Delta V$ & $\Delta H_{1}$ & $\Delta H_{2}$ & $\Delta H_{3}$ & $\Delta H_{4}$ & $\Delta H_{5}$ & $\frac{\min \left(\Delta H_{i}\right)}{\Delta V}$ & $\frac{\max \left(\Delta H_{i}\right)}{\Delta V}$ \\
\hline Bangladesh & 1 & 5 & $1.1 \%$ & $0.9 \%$ & $0.9 \%$ & $1.1 \%$ & $1.6 \%$ & $2.2 \%$ & 0.9 & 2.0 \\
\hline Indonesia & 2 & 5 & $0.4 \%$ & $2.6 \%$ & $2.2 \%$ & $2.2 \%$ & $2.3 \%$ & $2.7 \%$ & 4.8 & 6.1 \\
\hline Pakistan & 1 & 5 & $1.4 \%$ & $1.2 \%$ & $1.5 \%$ & $1.7 \%$ & $1.6 \%$ & $1.8 \%$ & 0.9 & 1.3 \\
\hline Philippines & 1 & 5 & $0.9 \%$ & $0.7 \%$ & $0.9 \%$ & $1.0 \%$ & $1.0 \%$ & $1.1 \%$ & 0.8 & 1.2 \\
\hline Turkey & 5 & 2 & $1.3 \%$ & $5.4 \%$ & $5.3 \%$ & $4.4 \%$ & $3.4 \%$ & $2.1 \%$ & 1.6 & 4.2 \\
\hline Vietnam & 1 & 4 & $1.6 \%$ & $3.1 \%$ & $3.7 \%$ & $3.0 \%$ & $2.6 \%$ & $2.3 \%$ & 1.4 & 2.3 \\
\hline
\end{tabular}

$Q_{\min }$ and $Q_{\max }$ refer to the quintile that is least or most affected at the median, respectively. $\Delta V$ denotes the difference between the median values of $Q_{\min }$ and $Q_{\max } . \Delta H_{i}$ refers to the difference between the 20 th and the 80 th percentile within each national quintile $i$. Note that underlying data were subject to outlier treatments and data cleaning (Methods and Supplementary Information). Differences between comparison column and $\Delta H$ or $\Delta V$ might arise from rounding up at all columns. Division is carried out with non-rounded values.

horizontal equity effects in Supplementary Tables 12-14. The difference between the median incidence of the most- and the least-affected quintile $(\Delta V)$ is particularly small in India and Indonesia (both $\sim 0.4 \%$ ), while for the other countries it is slightly larger. However, these differences are small compared to the variation within quintiles. For example, India and Indonesia exhibit 1.4 and a 2.6 percentage points differences, respectively, between the most and the least affected $20 \%$ in the first quintile $\left(\Delta H_{1}\right)$. Compared to vertical effects, the horizontal effects by quintile are 3.7-5.3 times larger for India and 4.8-6.1 times larger for Indonesia (comparison column, Table 1). Thailand and Turkey also display large discrepancies between vertical and horizontal effects. While the exact values on comparing vertical to horizontal effects are subject to the specific method chosen to calculate horizontal effects, the key result (that horizontal effects are more pronounced than vertical ones) also holds when applying different methodologies (Supplementary Tables 12-14).

To better understand the heterogeneity of affected households, Extended Data Fig. 1 shows the absolute distributional effects of a US $\$ 40$ per $\mathrm{tCO}_{2}$ carbon price for urban as well as rural households. In most countries, rural and urban households would be affected in rather similar ways. However, some notable exceptions exist. In Bangladesh and Pakistan, the rural poor would be least affected by a national carbon price and the urban rich the most. One explanation could be that the countries' poorest households are (1) mostly relying on subsistence farming and traditional fuels (which are difficult to tax) and (2) are mostly rural, while urban households-even when belonging to the poorest urban quintile-are still relatively rich compared to the country average (including rural areas). For Turkey, the urban rich show the lowest median impact as well as the lowest spread. That is, a substantially lower fraction of this population group would suffer income losses of $>5 \%$ compared to the urban poor as well as the rural population. This observation might be due to the fact that in Turkey, which is the richest country in our sample, poorer households spend a higher share of their income on energy-intensive goods and services-a pattern that has been consistently found for industrialized countries ${ }^{23}$.

Similar to what we find previously for the entire economies, when looking into urban and rural results separately, vertical interquintile differences are generally less pronounced than horizontal intraquintile ones, indicating that specific groups of the society would be particularly affected by carbon prices.

\section{Determinants of distributional effects}

Of all consumption categories (Supplementary Table 7 and Supplementary Figs. 5-8) energy is the most carbon-intensive one, hence differences in energy expenditures across quintiles are the main determinant of carbon pricing incidence (Supplementary Fig. 5). All countries show a positive correlation between energy expenditure shares and the incidence of a national carbon price (Supplementary Table 11). Thailand and Turkey are the only countries in which richer households tend to spend a lower share of their income on energy than poorer households, which is in line with the regressive results presented above. Note that Thailand and Turkey are also the richest countries in the sample, which generally tend to show more regressive results ${ }^{11}$. The regressive outcome observed for Thailand and Turkey is exacerbated by a relatively higher carbon intensity of the food sector (of which poorer household consume higher shares; Supplementary Fig. 8). Notably, Pakistan, India and Bangladesh show the least marked correlation (Supplementary Table 11). In these countries, other carbon-intensive expenditure categories also explain distributional effects. For the case of India, the effects correlate with consumption of food and consumption goods. Compared to other countries, in India, these categories are especially carbon-intensive (Supplementary Table 7). Given that poorer households tend to spend relatively more on consumption of goods and food (Supplementary Figs. 3, 7 and 8), carbon pricing in India is regressive. Pakistan on the other hand, has the least carbon-intensive food sector in the sample but a carbon-intensive service sector. Services are mostly consumed by richer households (Supplementary Fig. 3), which, together with the (marginally) larger share of energy expenditures, contributes to explaining progressive results.

Within energy expenditures, transport expenditures are related to progressive outcomes (Fig. 3). In all countries, the poorest households spend substantially less for transport as a share of their total expenditures than do richer ones. At the same time, the regressive incidence of a carbon price in Turkey and Thailand correlates with declining shares of electricity expenditures for richer households (Fig. 3). Furthermore, for Turkey, higher expenditure shares on coal for poorer households contribute to the observed regressive outcomes. In countries with higher levels of average income (Indonesia, Turkey, Vietnam and Thailand), electricity consumption shares decline with rising total expenditures while they tend to increase with rising expenditure shares in the other countries. The extensive use of biomass-which we consider not to be covered by a carbon price-in some countries can also explain the progressivity. This might be particularly true for Bangladesh where a large part of the poor population does not report expenditures for energy services, implying a high usage rate of non-marketed fuels (Fig. 4). Hence, poorer households, which use a higher share of biomass for their energy services, are less affected by carbon pricing. 

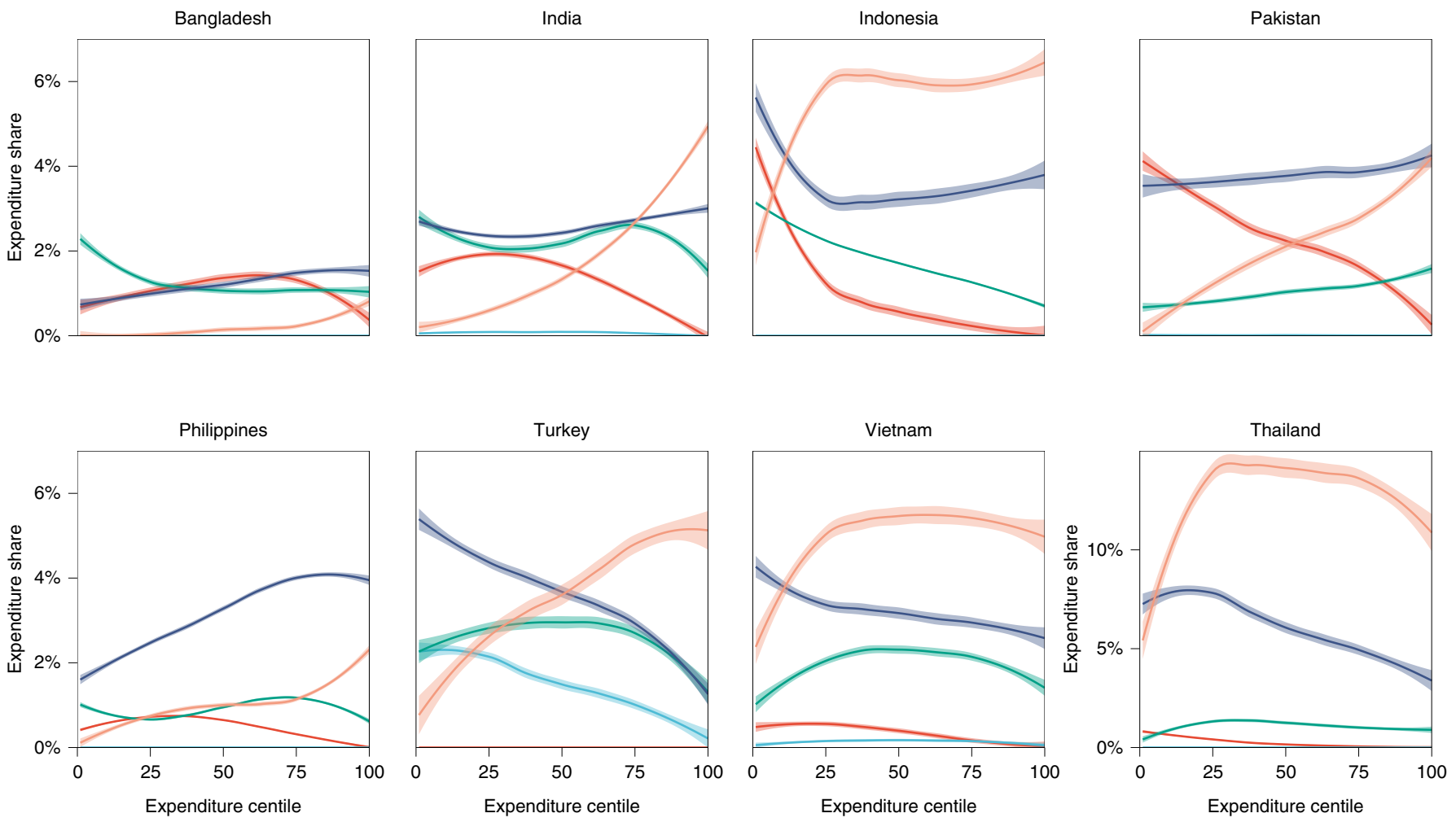

Biomass
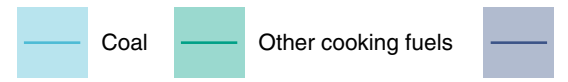

Electricity

Transport fuels

Fig. 3 | Variation of expenditures on energy services over expenditure centiles. Fitted lines are reported for a non-parametric Kernel density estimation of Engel curves for each energy consumption item calculated with country-specific microdata. Biomass comprises expenditures for charcoal and firewood; other cooking fuels include expenditures for kerosene, natural gas and LPG; transportation fuels comprise expenditures for diesel and petrol. Note the different $y$ axis for Thailand.

Large variations in transport-related expenditures are the main determinants of horizontal distributional effects (Fig. 4). This is outstanding for the case of India, for which we find the largest within-quintile variation of carbon pricing incidences for the fifth quintile (Table 1). This large variation is closely related to the large variation in transport expenditures within the fifth quintile (Fig. 4). A similar picture evolves for Indonesia. Looking into solid fuels, such as biomass and coal, biomass expenditures, presumably for cooking purposes, vary starkly for the poorest households in Indonesia and Pakistan. For Turkey, it appears that only specific households within the first quintile consume a large share of coal, presumably for heating. Finally, in all countries, we observe large variations in the expenditure shares for electricity.

\section{Socially just climate policy}

Comparing eight Asian, coal-investing countries we can unravel the distributional effects of climate policy. Addressing climate change successfully will need to take the social implications of policy measures into account, hence making sure that climate policy will not foster social inequalities. Generally, confirming results from previous studies ${ }^{11}$, we find that progressive outcomes of carbon pricing are more likely to be found in poorer countries. This can partly be explained by changing energy expenditure patterns (Fig. 3). One might argue that introducing climate policy early in the development phase might be easier as it implies fewer implications for social justice. Yet, the findings of our analysis emphasize the heterogeneity of distributional impacts of climate policies across different countries, various policy instruments as well as within individual income groups in each country.
For our scenario of a national carbon price, we find potential median country-wide income losses ranging from $1.1 \%$ to $4.6 \%$, depending on the country and income group. Differences in distributional effects between urban and rural areas are comparatively small for most countries. By contrast, for all countries, within-quintile differences are more pronounced than differences across quintiles.

To understand how climate policy instruments can be designed in a way that is perceived as socially just, it is important to look beyond the question of whether a certain carbon pricing design would have progressive or regressive distributional impacts ${ }^{24,25}$. Progressive outcomes would still affect households in absolute terms. Carbon pricing schemes have the power to raise revenues (in contrast to most alternatives, such as standards) that can be used to advance sustainable development by lowering distortionary taxes or providing cash transfers for the most affected households ${ }^{24}$. In addition, carbon pricing revenues could also mobilize domestic resources to fund central sustainable development objectives, such as healthcare, education or access to water, sanitation and clean energy ${ }^{26}$.

In this study, we have focused on the relationship between climate change mitigation and income distribution. Even though a detailed analysis of different revenue recycling options is beyond the scope of this paper, we provide some insights on how households would be affected if revenues of a national carbon price were fully recycled back to households on an equal per capita basis (Fig. 5 and Supplementary Table 18). In all countries, nearly all households in the poorest quintile would experience a positive change in 

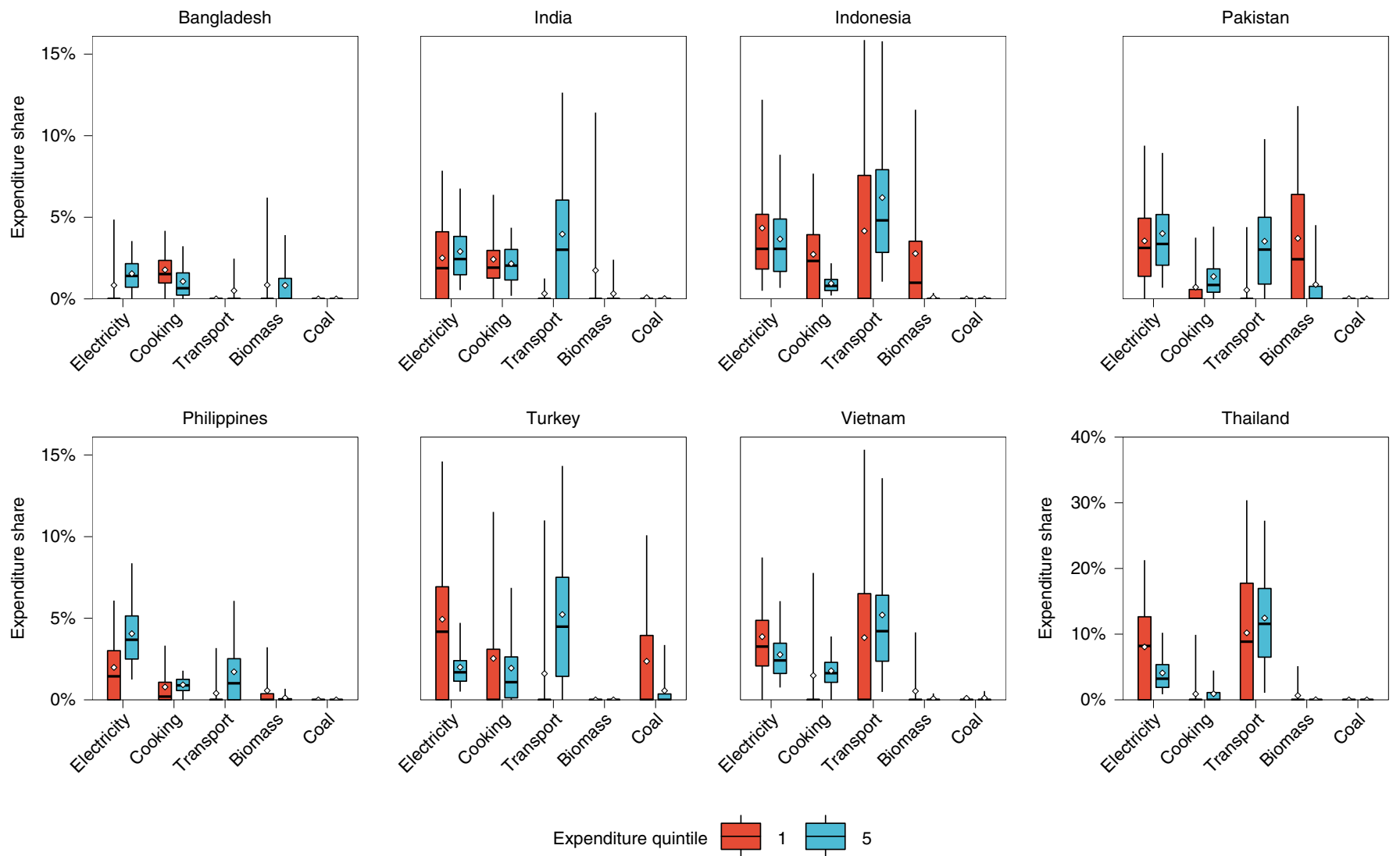

Expenditure quintile

Fig. 4 | Variation in expenditure shares for different energy services. Energy services include electricity, cooking, transportation, biomass and coal. Note that biomass only refers to marketed biomass. Colours refer to the first (red) and fifth (blue) quintile for each country. Dots indicate the mean. Black horizontal lines display the median. Boxes display the 25th to 75th percentile. Whiskers indicate the 5th to 95th percentile. Missing boxes refer to most households ( $>75 \%$ ) not reporting expenditures on related consumption items. Note the different $y$ axis for Thailand.

their household budgets. The highest increase of households budgets (median values) can be found in Thailand (14\%) and Vietnam (9.5\%). By contrast, while the relative burden on richer households would be eased by revenue recycling, only few households would actually experience net gains.

Yet, it is unlikely that countries are willing (and institutionally capable) to fully recycle revenues back to households. Some have proposed to use existing social transfer schemes to alleviate effects of climate policies ${ }^{25}$. In any case, designing compensation schemes tailored for the specific context in which they are introduced requires a close understanding of the factors that determine which households are most severely affected. Our results indicate that vulnerable population groups might be highly country-specific and most likely tied to specific energy and fuel use, for example the choice of the heating and cooking fuels, whether and how households use electricity and whether households own a motorized vehicle (Figs. 3 and 4). How those consumption patterns can be used to devise targeted compensation schemes (or additional policies that ease the transition to clean energies) is a promising area for further research.

Distributional consequences can be eased, thus raising the social acceptance by measures other than compensation schemes. Regarding electricity, for example, where electricity supply is relatively clean, electricity expenditures do not play a major role for the distributional effects of carbon pricing. By contrast, a carbonizing electricity sector (which is likely for all eight countries under consideration) will change the distributional incidence towards more progressivity or regressivity, depending on whether richer or poorer households exhibit higher electricity expenditure shares. Hence, avoiding future carbonization of those countries' energy sectors will also alleviate distributional concerns of introducing climate policies in the future. The literature has identified a role for the international community here, for example by de-risking investments to render clean alternatives more attractive ${ }^{27}$.

Differences in electrification rates and biomass use also play a major role in how households are affected by climate policy. In cases in which poor households heavily rely on biomass, the distributional incidence of carbon pricing is probably progressive. However, in such situations carbon pricing might provide incentives to use more biomass ${ }^{28}$, with potential adverse health consequences due to indoor air pollution ${ }^{29}$, and shifts in female labour force and education, as women and children dedicate a larger share of their time to firewood collection ${ }^{30}$. To avoid those potential trade-offs for sustainable development, exempting some fuels that are particularly prone to substitution by traditional biomass (such as liquefied petroleum gas (LPG) for cooking) from carbon pricing or subsidizing clean alternatives, such as fostering the uptake of clean stoves ${ }^{31}$ could be ways to address this concern.

Finally, while we focus on carbon pricing schemes and their design options, other policy instruments could be used to tackle the electricity sector directly, such as coal moratoria or performance standards. Alternative climate policies, for example standards, moratoria or subsidies in the electricity sector, might face lower public resistance ${ }^{32}$. Yet, the potential subsequent increase in electricity prices can also induce negative distributional consequences for households, which could lead to political opposition to such reforms. For example, in Germany, feed-in tariffs to foster renewable energy uptake have increased electricity prices 

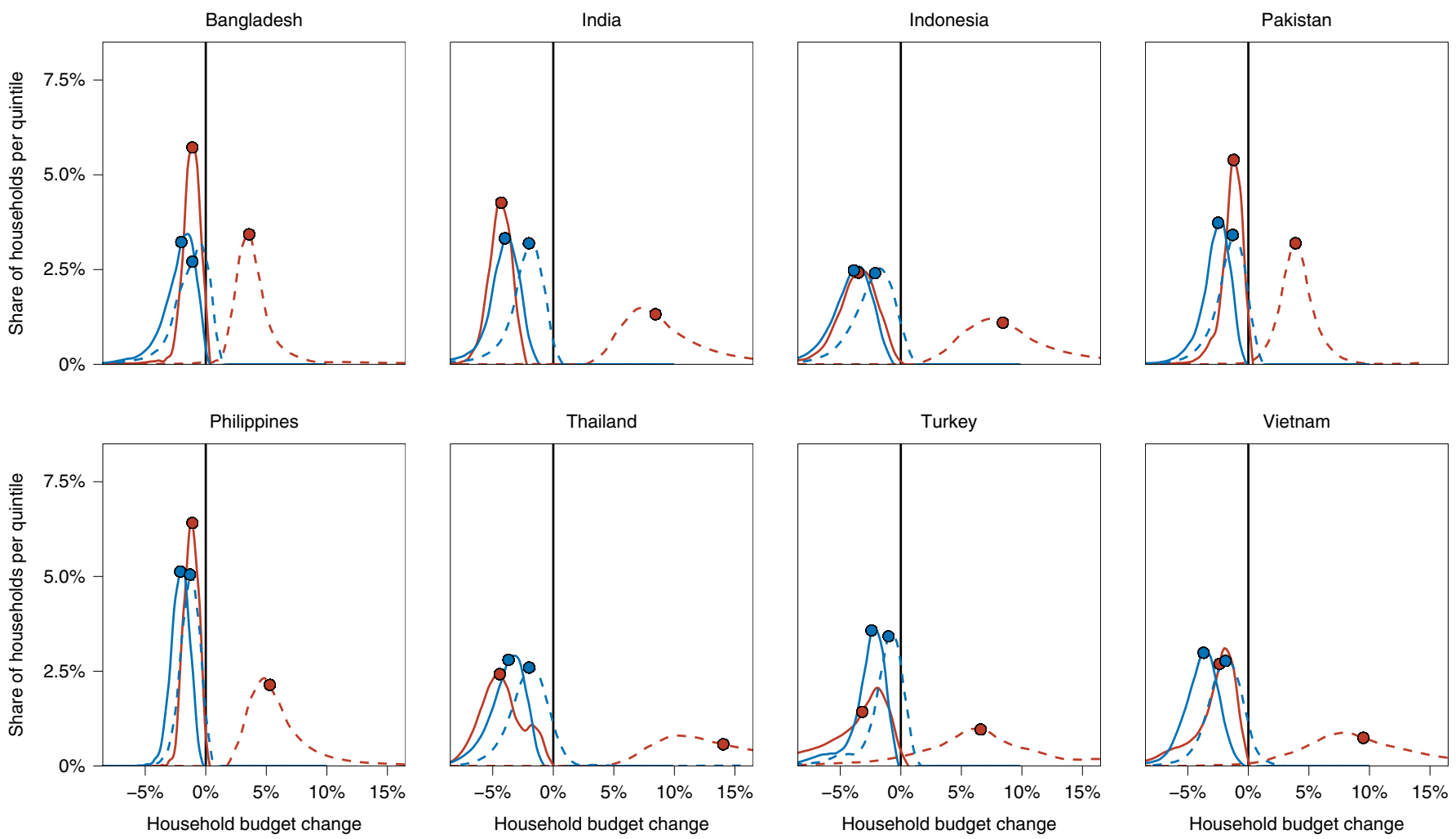

$$
\begin{aligned}
& \text { - National carbon price (expenditure quintile 1) } \\
& \text { - }- \text { - National carbon price (expenditure quintile 5) } \\
& \text { - }- \text { - National carbon price and equal per capita transfer (expenditure quintile 1) }
\end{aligned}
$$

Fig. 5 | Distribution of the incidence of a national carbon price with equal per capita transfer for first and fifth quintile. Each smoothed density curve refers to the distribution of household budget change for a US $\$ 40$ per $\mathrm{tCO}_{2}$ carbon price and an equal per capita lump sum transfer respectively ( $x$ axis). The $y$ axis displays the share of households within each quintile. Curves are fitted over binned incidence levels with $\Delta x=0.1 \%$. Solid curves display the negative household budget change; dashed curves represent the household budget change if revenues from the carbon price were distributed equally per capita. Dots correspond to median values. Cumulative densities sum up to $100 \%$. Supplementary Table 18 lists summary statistics for all expenditure quintiles.

for households and are highly regressive ${ }^{33}$. For the set of eight Asian countries, an increase in electricity prices would have comparable distributional outcomes to a sectoral carbon price in the power sector; it would hence be more regressive than a national carbon price in India, Pakistan, Thailand, Turkey and Vietnam (Supplementary Fig. 9).

Disentangling distributional incidences across eight Asian countries reveals highly country-specific effects. Those need to be taken into account when designing compensation schemes and-accordingly-specific policies. While its simplicity makes carbon pricing appealing in economic theory, alleviating heterogeneous implications on households as well as on other sustainable development goals will be key for its actual implementation.

\section{Methods}

We merge multiregional input-output (MRIO) data and multiple region-specific household survey datasets. We use the MRIO data to assess household carbon footprints and electricity footprints of consumption.

To make results comparable across income groups, we express the incidence as share of total yearly household expenditures (Fig. 2). This ensures comparability of distributional outcomes across countries. We normalize median incidences for expenditure quintiles to the impact of the poorest household expenditure quintile in each region to compare distributional effects across instruments (Fig. 1).
Data. For our analysis we use the Global Trade Analysis Project 10 (GTAP) database $^{34}$ for the year 2014 and convert it into an MRIO table (Peters et al. ${ }^{35}$ ). The GTAP database considers 65 homogenized sectors and 141 regions. GTAP's environmental satellite data account for emissions released during sectoral production processes, as well as emissions related to direct household consumption. As there are no single annual releases of GTAP, not all household data and MRIO data have the same reference year. We account for this by inflating household consumption data to the base year 2014 (Supplementary Information).

Matching. A crucial step within our analysis framework is the matching of the highly detailed and region-specific household data with the GTAP sectors. Supplementary Table 1 provides an overview of the different household survey data. Supplementary Tables 2 and 3 list summary statistics for each countries' data. Survey data were collected with the help of standardized surveys during face-to-face visits in single households and are nationally representative. Datasets differ regarding the number of items reported, number of households considered, currencies or time horizons for reporting. We thus homogenize the datasets to ensure comparability and report additional cleaning steps in the Supplementary Information. The number of categories of the household data (up to 640 in case of Pakistan) and the GTAP categories (65) differ substantially. Household data need to be aggregated to the sectoral GTAP level for each survey separately. GTAP provides a detailed overview of commodities contained within single sectors ${ }^{34}$. For each regional household survey, we therefore investigate which items belong to which GTAP category (Supplementary Information).

Calculation of sectoral embedded carbon intensities. Standardized MRIO data account for a specific number of regions $n$ and a specific number of sectors 
$m$. They consist of an interindustry flow matrix $Z \in \mathbb{R}^{(m \times n) \times(m \times n)}$ and a final demand vector $\mathbf{Y} \in \mathbb{R}^{m \times n \times n}$, see for example ref. ${ }^{36}$. Entries $z_{r_{1} s_{1}}^{r_{2} s_{2}}$ of $Z$ reflect the total monetary value (in US\$) of flows from sector $s_{1}$ in region $r_{1}$ to sector $s_{2}$ in region $r_{2}$ with $r_{1}, r_{2} \in\{1, \ldots, n\}$ and $s_{1}, s_{2} \in\{1, \ldots, m\}$. Analogously, for the single entries of $\mathbf{Y}, c_{r_{1}, s_{1}}^{r_{2}}$ represents the sum of all monetary flows from sector $s_{1}$ of region $r_{1}$ into final consumption $c$ ( $c$ is used for demand) of region $r_{2}$. Let $y^{\mathrm{HH}}$ denote the final consumption that is due to households.

These can be used to calculate the total output vector $\mathbf{O} \in \mathbb{R}^{m \times n}$, with entries

$$
o_{r_{1}, s_{1}}=\sum_{s} \sum_{r}\left(z_{r_{1} s_{1}}^{r, s}\right)+\sum_{r} c_{r_{1}, s_{1}}^{r}
$$

By $A \in \mathbb{R}^{(m \cdot n) \times(m \cdot n)}$ we denote the technology matrix, with entries

$$
a_{r_{1} s_{1}}^{r_{2} s_{2}}=z_{r_{1} s_{1}}^{r_{2} s_{2}} / o_{r_{2}, s_{2}}
$$

These describe the amount of each input that is necessary to produce one unit of output.

The Leontief inverse $L$, which accounts for all preproducts that have been used at some stage during production, is calculated as

$$
L=(I-A)^{-1}
$$

where $I$ denotes the identity matrix.

Let $\mathbf{F} \in \mathbb{R}^{m \times n}$ denote the vector whose elements $\mathrm{F}_{r, s}$ denote total emissions released by sector $s$ in region $r$. Dividing $\mathbf{F}$ entry-wise by total sectoral outputs $\mathbf{O}$ results in vector $\mathbf{f}$ whose entries reflect $\mathrm{CO}_{2}$ emissions associated with one US\$ of output (emissions intensity) of sector $s_{1}$ in region $r_{1}$, that is the carbon intensity. Let $F_{r_{1} s_{1}}^{\mathrm{dir}}$ denote the direct emissions of households in region $r_{1}$, sector $s_{1}$ that are accounted for in the GTAP database.

International carbon price (case 1). For each region of our study we first calculate embedded carbon emission intensities from GTAP data. Embedded carbon intensities include both indirect emissions and direct household emissions. Second, total embedded carbon emission intensities are matched with household survey data. This allows for deriving the level of emissions embedded in a household's final consumption

We calculate embedded carbon emission intensities as derived from GTAP. The total indirect emissions $\widehat{F H}_{r, s}$ that households in region $r_{1}$ of commodity $s_{1}$ consume is given by:

$$
\widehat{F H}_{r_{1} s_{1}}=\sum_{r \prime} \sum_{s \prime} \sum_{r} f_{r /, s \prime} L_{r \prime, s l}^{r, s_{1}} y_{r, s_{1}}^{H H, r_{1}}
$$

Adding the direct emissions yields the total amount of emissions for households $\mathrm{F}$ that is relevant for our study, that is $F_{r_{1} s_{1}}=F_{r_{1} s_{1}}^{\mathrm{dir}}+\widehat{F H}_{r_{1} s_{1}}$. We derive sectoral embedded carbon emissions intensity $C_{r_{1} s_{1}}$ by using total household expenditures $y_{r, s_{1}}^{H H r_{1}}$ in region $r_{1}$ of commodity $s_{1}$ from GTAP as a denominator:

$$
C I_{r_{1} s_{1}}=\frac{F_{r_{1} s_{1}}}{y_{r, s_{1}}^{H H, r_{1}}}
$$

See Supplementary Table 8 and Supplementary Information for an overview of derived embedded carbon intensities in this study.

We then calculate embedded carbon emissions of household consumption of individual households, which we denote with $f e$. We merge derived embedded carbon emission intensities with individual household datasets. Each household $k$ in region $r_{1}$ reports expenditures $E x p_{r, s}^{k}$ in different sectors $s$.

Total embodied emissions $f e_{r_{1}}^{k_{1}}$, which are virtually contained in $\operatorname{Exp}_{r_{1}}$, the total amount of expenditures of household $k_{1}$ in region $r_{1}$, are given by:

$$
f e_{r_{1}}^{k_{1}}=\sum_{s} \operatorname{Exp}_{r_{1}, s}^{k_{1}} \cdot C I_{r_{1}, \mathrm{~s}}
$$

Thus, we attribute higher levels of $f e_{r}^{k}$ to those households, which allocate more money to the consumption of more carbon-intensive goods. We then apply a carbon price and assess additional costs for individual households. Applying a carbon price $t$ would then require each household to bear additional costs, if current levels of consumption are to be maintained. For household $k_{1}$ in region $r_{1}$ these additional costs $A C_{r_{1}}^{k_{1}}$ are then $A C_{r_{1}}^{k_{1}}=t \cdot f e_{r_{1}}^{k_{1}}$ with carbon tax $t$. Relative costs increases $a c_{r_{1}}^{k_{1}}$ result from:

$$
a c_{r_{1}}^{k_{1}}=\frac{A C_{r_{1}}^{k_{1}}}{\operatorname{Exp}_{r_{1}}^{k_{1}}}=\frac{t \cdot f e_{r_{1}}^{k_{1}}}{\operatorname{Exp}_{r_{1}}^{k_{1}}}
$$

Throughout this study, we refer to $a c_{r_{1}}^{k_{1}}$ as the incidence of carbon pricing for household $k_{1}$ in region $r_{1}$ or as absolute effects.

To compare the vertical distribution of incidences across countries, we cluster households into quintiles on the basis of total household expenditures per capita. Let $\widetilde{a c}_{r_{1}}^{j}$ denote the median incidence from carbon pricing for each quintile $j$ in region $r_{1}$. We derive $\overrightarrow{a c}_{r_{1}}^{j}$ by using $\widetilde{a c}_{r_{1}}^{1}$ as a denominator as in

$$
\overline{a c}_{r_{1}}^{j}=\frac{\widetilde{a c}_{r_{1}}^{j}}{\widetilde{a c} c_{r_{1}}^{1}}
$$

Subsequently, $\overline{\operatorname{ac}}_{r_{1}}^{j}$ indicates the median incidence of quintile $j$ in region $r_{1}$ in comparison to the poorest quintile in region $r_{1}$. We refer to $\overline{\mathrm{ac}}_{r_{1}}^{j}$ as relative effects. We show $\overline{\mathrm{ac}}_{r_{1}}^{j}$ for different instruments and regions in Fig. 1.

National carbon price (case 2). The strategy and calculations of case 2 are identical to case 1 but with the difference that only national emissions are considered in equation (4). Technically, a relevant share of emissions contained in the emission vector is thus treated as zero. In equation (4), all elements $f_{\mathrm{r}^{\prime}}, \mathrm{s}^{\prime}$ with $\mathrm{r}^{\prime} \neq \mathrm{r}_{n}$ are set zero, thus

$$
f_{\mathrm{r}^{\prime}, \mathrm{s}^{\prime}}=\left[\begin{array}{ccccccc}
0 & \cdots & 0 & f_{r_{n} s_{1}} & 0 & \cdots & 0 \\
\vdots & \ddots & \vdots & \vdots & \vdots & \ddots & \vdots \\
0 & \cdots & 0 & f_{r_{n} s^{\prime}} & 0 & \cdots & 0 \\
\vdots & \ddots & \vdots & \vdots & \vdots & \ddots & \vdots \\
0 & \cdots & 0 & f_{r_{n} s_{m}} & 0 & \cdots & 0
\end{array}\right]
$$

Emissions from production processes in regions other than region $r^{\prime}$ are disregarded for calculating total indirect emissions embedded in consumption $\widehat{F H}_{r . s}$. In theory, this implies the absence of any carbon border tax adjustment mechanism. Hence, $C_{r_{1}, s_{1}}^{\text {case } 2} \leq C I_{r_{1}, s_{1}}^{\text {case } 1}$ holds.

Electricity sector and liquid fuel carbon prices (cases 3 and 4). In these cases, we study national carbon prices, which apply in the power sector or transport sector only. Similarly to case 2, we include national emissions only. The sectoral carbon price is next modelled by setting all elements $f_{\mathrm{r} / \mathrm{s} /}$ of the emissions vector with $\mathrm{r}^{\prime} \neq \mathrm{r}_{1}$ and $\mathrm{s}^{\prime} \neq \mathrm{s}_{1}$ to zero. For the electricity sector carbon price, $s_{1}=\{$ ely $\}$. Thus, we only include emissions released in the electricity sector. For the liquid fuel carbon price, $s_{1}=\left\{p_{-} c\right.$, otp, atp, wtp $\}$. In our model, we include only emissions released during the use of petroleum (p_c), land transport (otp), water transport (wtp) and air transport (atp). Note that matching GTAP with item level consumption data constrains the analysis of a transport sector carbon price, which is the purpose of this exercise. Therefore our modelling outcomes could be best regarded as a price on carbon emitted from the use of liquid fuels including emissions from the transport sector. We show the distributional implications only (Fig. 1) and report the incidence for these policies in detail (Supplementary Tables 9 and 10).

National power sector instruments (case 5). Here we consider (direct and indirect) electricity consumption only. The underlying rationale is that approaches to directly reduce coal use (such as performance standards or moratoria) would probably raise electricity prices. We exchange the emissions vector $\mathbf{F}$ in (4) with the monetary electricity output vector EL from GTAP. For all non-electricity sectors, its entries are zero. For all electricity sectors the entries refer to total electricity that is being produced and consumed. We assume that the underlying virtual electricity flows are proportional to monetary flows; that is, that all economic sectors pay the identical price for electricity. We thus derive $\mathrm{EEI}_{r_{1} s_{1}}$, which refers to the amount of money spent on electricity embedded in one unit of household consumption of sector $s_{1}$ in country $r_{1}$. As for case 3 , we assess the relative distributional implications only (Supplementary Figure 9). Thus, our results do not depend on the size of the electricity price increase. However, we report total expenditures on electricity embedded in total consumption for each country and quintile in Supplementary Table 9. Supplementary Table 10 reports the incidence of an (hypothetical) electricity price increase of $25 \%$.

Determinants of distributional effects. We identify determinants of distributional effects between expenditures shares by estimating a univariate regression:

$$
\mathrm{ac}_{r_{1}}^{k_{1}}=\beta_{0}+\beta_{1} \text { Share }_{k_{1}, r_{1}, v}+\varepsilon_{k_{1} r_{1}}
$$

where $\mathrm{ac}_{r_{1}}^{k_{1}}$ indicates the incidence of a national carbon price for a household $k_{1}$ in region $r_{1}$ and Share $k_{k_{1}, r_{1}, v}$ is the share over total expenditures of the consumption category $v$ where $v=\{$ energy, food, goods, services $\}$. We estimate a separate regression for each country and for each consumption category (results for energy, services, goods and food are reported in Supplementary Figs. 5, 6, 7 and 8). We also report the Pearson correlation coefficient between total expenditures and each consumption category $v$ (Supplementary Table 11).

To further analyse why households are impacted differently in each country, we estimate Engel curves ${ }^{37}$ using a non-parametric locally weighted regression estimator $^{38}$ (Fig. 3 and Supplementary Fig. 3). For each country we estimate the relationship between total household expenditures and expenditures shares separately for different types of energy services. Supplementary Table 6 provides an overview of the specific fuels included in each category. 
Reporting Summary. Further information on research design is available in the Nature Research Reporting Summary linked to this article.

\section{Data availability}

Microdata from household surveys are available on request from related statistical offices. Note that restrictions and fees apply. Country-specific trade and emissions data are available from GTAP10 (https://www.gtap.agecon.purdue. edu/default.asp) subject to fees. Both microdata from household surveys and GTAP are available from the authors on reasonable request and conditional on approval by the responsible statistical offices or GTAP, respectively. Aggregate data on the household level can be accessed via https://github.com/lmissbach/ DIDA_SI. Data on electricity generation are accessible from IEA's World Energy Balances 2020 Data Browser (https://www.iea.org/data-and-statistics). Aggregate summary statistics on single countries are available in the WorldBank's World Development Indicators (https://databank.worldbank.org/source/ world-development-indicators\#). Global Energy Monitor provides data on current and prospective coal plants (https://globalenergymonitor.org/projects/ global-coal-plant-tracker/summary-data/). The International Monetary Fund provides data on consumer price indices (https://www.imf.org/en/Publications/ WEO/weo-database/2020/October).

\section{Code availability}

Code written for this analysis can be found along with aggregated datasets here: https://github.com/lmissbach/DIDA_SI. In addition, we used Data Browser from World Energy Balances 2020 (International Energy Agency) to access data on electricity generation. We used World Development Indicators DataBank (WorldBank) to access aggregate summary statistics. We used Global Coal Plant Tracker (Global Energy Monitor) to access data on coal plant investments. We used World Economic Outlook Database (International Monetary Fund) to access consumer price indices

Received: 1 March 2021; Accepted: 13 July 2021;

Published online: 23 September 2021

\section{References}

1. State and Trends of Carbon Pricing 2021 (World Bank, 2021); https:// openknowledge.worldbank.org/handle/10986/35620

2. Shearer, C. et al. Boom and Bust 2020: Tracking the Global Coal Plant Pipeline (2020); https://endcoal.org/wp-content/uploads/2020/03/BoomAndBust_ 2020_English.pdf

3. Edenhofer, O., Steckel, J. C., Jakob, M. \& Bertram, C. Reports of coal's terminal decline may be exaggerated. Environ. Res. Lett. 13, 024019 (2018).

4. Tong, D. et al. Committed emissions from existing energy infrastructure jeopardize $1.5^{\circ} \mathrm{C}$ climate target. Nature 572, 373-377 (2019).

5. Andrijevic, M., Schleussner, C.-F., Gidden, M. J., McCollum, D. L. \& Rogelj, J COVID-19 recovery funds dwarf clean energy investment needs. Science 370, 298 (2020).

6. Bertram, C. et al. COVID-19-induced low power demand and market forces starkly reduce $\mathrm{CO}_{2}$ emissions. Nat. Clim. Change 11, 193-196 (2021).

7. Cramton, P., MacKay, D. J., Ockenfels, A. \& Stoft, S. Global Carbon Pricing: The Path to Climate Cooperation (The MIT Press, 2017).

8. Drews, S. \& van den Bergh, J. C. J. M. What explains public support for climate policies? A review of empirical and experimental studies. Clim. Policy 16, 855-876 (2016).

9. Pachauri, S. Household electricity access a trivial contributor to $\mathrm{CO}_{2}$ emissions growth in India. Nat. Clim. Change 4, 1073-1076 (2014).

10. Rauner, S. et al. Coal-exit health and environmental damage reductions outweigh economic impacts. Nat. Clim. Change 10, 308-312 (2020).

11. Ohlendorf, N., Jakob, M., Minx, J. C., Schröder, C. \& Steckel, J. C. Distributional impacts of carbon pricing: a meta-analysis. Environ. Resour. Econ. 78, 1-42 (2021).

12. Dorband, I. I., Jakob, M., Kalkuhl, M. \& Steckel, J. C. Poverty and distributional effects of carbon pricing in low- and middle-income countries-a global comparative analysis. World Dev. 115, 246-257 (2019).

13. Vogt-Schilb, A. et al. Cash transfers for pro-poor carbon taxes in Latin America and the Caribbean. Nat. Sustain. 2, 941-948 (2019).

14. Feindt, S., Kornek, U., Labeaga Azcona, J. M., Sterner, T. \& Ward, H. Understanding Regressivity: Challenges and Opportunities of European Carbon Pricing (SSRN, 2020); https://doi.org/10.2139/ssrn.3703833

15. Cronin, J. A., Fullerton, D. \& Sexton, S. Vertical and horizontal redistributions from a carbon tax and rebate. J. Assoc. Environ. Resour. Econ. 6, S169-S208 (2019)

16. Fischer, C. \& Pizer, W. A. Horizontal equity effects in energy regulation. J. Assoc. Environ. Resour. Econ. 6, S209-S237 (2019).

17. Stiglitz, J. \& Stern, N. Report of the High-Level Commission on Carbon Prices (Carbon Pricing Leadership Coalition, 2017).

18. Sterner, T. Fuel Taxes and the Poor: The Distributional Effects of Gasoline Taxation and Their Implications for Climate Policy (Routledge, 2012).
19. del Granado, F. J. A., Coady, D. \& Gillingham, R. The unequal benefits of fuel subsidies: a review of evidence for developing countries. World Dev. 40, 2234-2248 (2012).

20. Blundell, R. \& Preston, I. Consumption inequality and income uncertainty. Q. J. Econ. 113, 603-640 (1998).

21. Atkinson, A. B. \& Bourguignon, F. Handbook of Income Distribution Vol. 2 (Elsevier, 2014).

22. Edenhofer, O. et al. Closing the emission price gap. Glob. Environ. Change 31, 132-143 (2015)

23. Lamb, W. F. et al. What are the social outcomes of climate policies? A systematic map and review of the ex-post literature. Environ. Res. Lett. 15, 113006 (2020)

24. Klenert, D. et al. Making carbon pricing work. Nat. Clim. Change 8, 669-677 (2018)

25. Schaffitzel, F., Jakob, M., Soria, R., Vogt-Schilb, A. \& Ward, H. Can government transfers make energy subsidy reform socially acceptable? A case study on Ecuador. Energy Policy 137, 111120 (2019).

26. Franks, M., Lessmann, K., Jakob, M., Steckel, J. C. \& Edenhofer, O. Mobilizing domestic resources for the Agenda 2030 via carbon pricing. Nat. Sustain. 1, 350-357 (2018).

27. Steckel, J. C. \& Jakob, M. The role of financing cost and de-risking strategies for clean energy investment. Int. Econ. 155, 19-28 (2018).

28. Aggarwal, R., Ayhan, S., Jakob, M. \& Steckel, J. C. Carbon Pricing and Household Welfare: Evidence from Uganda Duke Global Working Paper Series No. 38 (SSRN, 2021); https://doi.org/10.2139/ssrn.3819959

29. Olabisi, M., Tschirley, D. L., Nyange, D. \& Awokuse, T. Energy demand substitution from biomass to imported kerosene: evidence from Tanzania. Energy Policy 130, 243-252 (2019).

30. Dinkelman, T. The effects of rural electrification on employment: new evidence from South Africa. Am. Econ. Rev. 101, 3078-3108 (2011)

31. Jeuland, M. et al. Is energy the golden thread? A systematic review of the impacts of modern and traditional energy use in low- and middle-income countries. Renew. Sustain. Energy Rev. 135, 110406 (2021).

32. Douenne, T. \& Fabre, A. French attitudes on climate change, carbon taxation and other climate policies. Ecol. Econ. 169, 106496 (2020).

33. Winter, S. \& Schlesewsky, L. The German feed-in tariff revisited-an empirical investigation on its distributional effects. Energy Policy 132, 344-356 (2019).

34. Aguiar, A., Chepeliev, M., Corong, E., McDougall, R. \& van der Mensbrugghe, D. The GTAP Data Base: Version 10. J. Glob. Econ. Analys. 4, 1-27 (2019).

35. Peters, G. P., Andrew, R. \& Lennox, J. Constructing an environmentallyextended multi-regional input-output table using the GTAP database. Econ. Syst. Res. 23, 131-152 (2011).

36. Stadler, K. et al. EXIOBASE 3-developing a time series of detailed environmentally extended multi-regional input-output tables. J. Ind. Ecol. 22 502-515 (2018)

37. Engel, E. Die Lebenskosten Belgischer Arbeiter-Familien Früher und Jetzt (C. Herinrich, 1895)

38. Cleveland, W. S. \& Devlin, S. J. Locally weighted regression: an approach to regression analysis by local fitting. J. Am. Stat. Assoc. 83, 596-610 (1988).

39. World Development Indicators | DataBank (World Bank, 2020); https:// databank.worldbank.org/source/world-development-indicators

40. Global Coal Plant Tracker (Global Energy Monitor, 2021); https://docs.google com/spreadsheets/d/1W-gobEQugqTR_PP0iczJCrdaR-vYkJ0DzztSsCJXuKw/ edit\#gid=822738567

\section{Acknowledgements}

We thank participants of the 2019 annual conference of the Environment for Development Network and the EAERE 25 postconference workshop on 'The Economics of Inequality and the Environment', as well as L. Mattauch and S. Carlsson Jagers for helpful comments and suggestions. We acknowledge funding from German Federal Ministry of Education and Research (01LS10A, pep1p5; I.I.D., L. Montrone, J.C.S. and H.W.), the Volkswagen Foundation (CoCCCo; L. Missbach) and the GIZ (81250748, 'DRM'; S.R.). L. Missbach further acknowledges funding through the German Federal Environmental Foundation. I.I.D. further acknowledges funding through the Heinrich Böll Foundation. The funders had no role in study design, data collection and analysis, decision to publish or preparation of the manuscript.

\section{Author contributions}

J.C.S., M.J., L. Montrone, L. Missbach, I.I.D., H.W. and S.R. conceived and designed the experiments. I.I.D., L. Montrone, L. Missbach, H.W., F.H. and J.C.S. performed the experiments. J.C.S., I.I.D., L. Montrone, L. Missbach, M.J. and S.R. analysed the data. H.W. contributed materials and analysis tools. J.C.S., M.J., L. Montrone and L. Missbach wrote the paper.

\section{Competing interests}

The authors declare no competing interests. 


\section{Additional information}

Extended data is available for this paper at https://doi.org/10.1038/s41893021-00758-8.

Supplementary information The online version contains supplementary material available at https://doi.org/10.1038/s41893-021-00758-8.

Correspondence and requests for materials should be addressed to Jan C. Steckel.
Peer review information Nature Sustainability thanks Anders Fremstad and the other anonymous, reviewer(s) for their contribution to the peer review of this work.

Reprints and permissions information is available at www.nature.com/reprints.

Publisher's note Springer Nature remains neutral with regard to jurisdictional claims in published maps and institutional affiliations.

(C) The Author(s), under exclusive licence to Springer Nature Limited 2021 

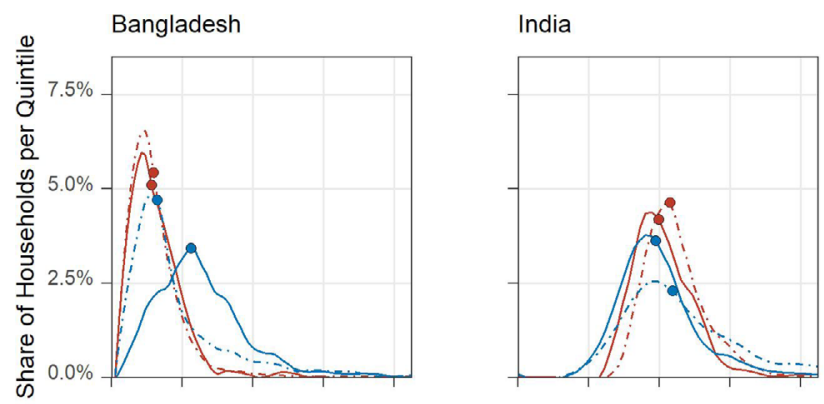

Indonesia

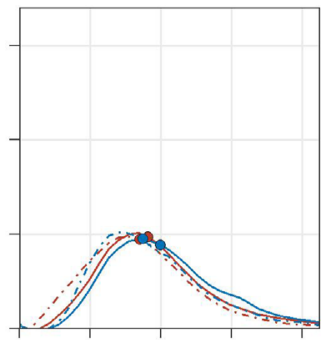

Thailand

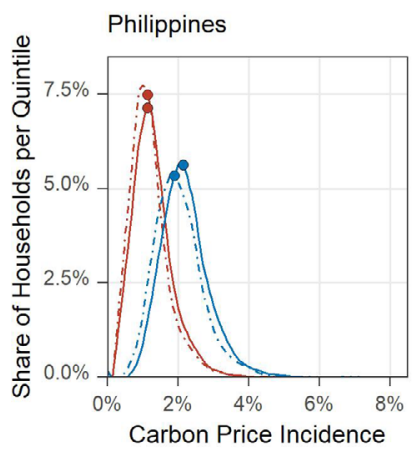

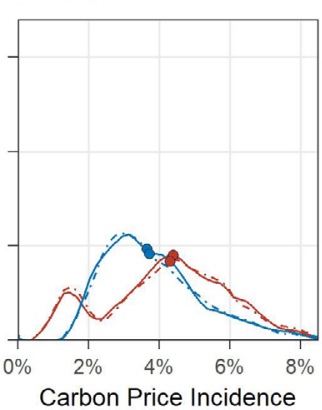

Carbon Price Incidence
Turkey

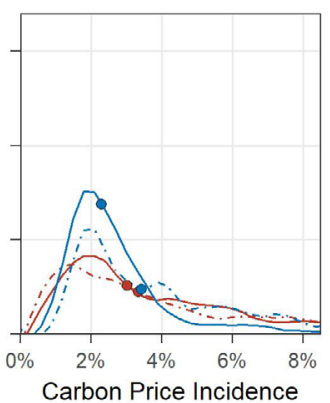

Pakistan

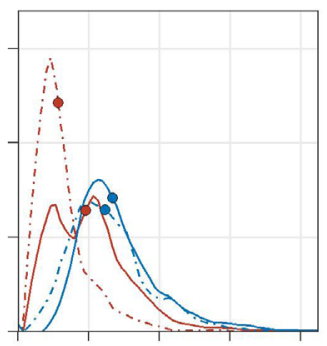

Vietnam

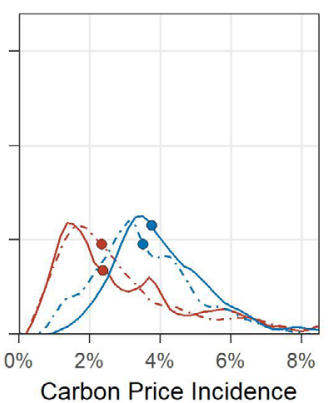

Expenditure Quintile $\multimap 1 \multimap 5$

Extended Data Fig. 1 | Distribution of the Incidence of a National Carbon Price for the first and fifth Quintile in Rural and Urban Areas. Each smoothed density curve refers to the distribution of cost burden as percent of household expenditures for a USD 40 per $\mathrm{tCO}_{2}$ carbon price ( $x$ axis). The y axis displays the share of households within each quintile. Curves are fitted over binned incidence levels with $\Delta x=0.1 \%$. Solid (dashed) lines refer to urban (rural) households, red (blue) lines refer to the $1^{\text {st }}\left(5^{\text {th }}\right)$ expenditure quintile. Dots correspond to median values. Note that households were assigned to expenditure quintiles first, that is the number of households for each curve differs. Any given expenditure quintile is the more affected the more its curve is skewed to the right. Households within expenditure quintiles are more heterogeneously affected, if curves are more widespread. Cumulative densities sum up to $100 \%$. 
Extended Data Table 1 | Overview of key socio-economic indicators in eight sample countries

\begin{tabular}{|c|c|c|c|c|}
\hline Country & Population (Million) & $\begin{array}{l}\text { GDP per capita ( } 2019 \\
\text { current USD) }\end{array}$ & $\begin{array}{l}\mathrm{CO}_{2} \text { Emissions per } \\
\text { capita }(\mathrm{t})\end{array}$ & $\begin{array}{l}\text { Coal (Under Construction and } \\
\text { Planned) (GW) }\end{array}$ \\
\hline Bangladesh & 163 & 1,855 & .5 & 21.7 \\
\hline India & 1,366 & 2,099 & 1.8 & 65.9 \\
\hline Indonesia ${ }^{a}$ & 270 & 4,135 & 2.2 & 32.9 \\
\hline Pakistan ${ }^{a}$ & 216 & 1,284 & 1.0 & 7.4 \\
\hline Philippines & 108 & 3,485 & 1.2 & 8.6 \\
\hline Turkeya & 83 & 9,126 & 4.7 & 20.4 \\
\hline Vietnam $^{a}$ & 96 & 2,715 & 2 & 28.7 \\
\hline Total & 2,371 & $2,740^{b}$ & $1.8^{\mathrm{b}}$ & $186.3^{c}$ \\
\hline
\end{tabular}

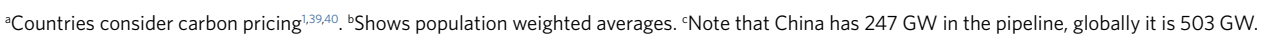




\section{Reporting Summary}

Nature Research wishes to improve the reproducibility of the work that we publish. This form provides structure for consistency and transparency in reporting. For further information on Nature Research policies, see our Editorial Policies and the Editorial Policy Checklist.

\section{Statistics}

For all statistical analyses, confirm that the following items are present in the figure legend, table legend, main text, or Methods section.

n/a Confirmed

Х $\square$ The exact sample size $(n)$ for each experimental group/condition, given as a discrete number and unit of measurement

Х $\square$ A statement on whether measurements were taken from distinct samples or whether the same sample was measured repeatedly

$\triangle \square$ The statistical test(s) used AND whether they are one- or two-sided

$\triangle$ Only common tests should be described solely by name; describe more complex techniques in the Methods section.

Х $\square$ A description of all covariates tested

$\bigotimes \square$ A description of any assumptions or corrections, such as tests of normality and adjustment for multiple comparisons

$\square$ A full description of the statistical parameters including central tendency (e.g. means) or other basic estimates (e.g. regression coefficient)

$\bigotimes \square$ AND variation (e.g. standard deviation) or associated estimates of uncertainty (e.g. confidence intervals)

$\bigotimes \square \begin{aligned} & \text { For null hypothesis testing, the test statistic (e.g. } F, t, r \text { ) with confidence intervals, effect sizes, degrees of freedom and } P \text { value noted } \\ & \text { Give } P \text { values as exact values whenever suitable. }\end{aligned}$

\ $\square$ For Bayesian analysis, information on the choice of priors and Markov chain Monte Carlo settings

Х $\square$ For hierarchical and complex designs, identification of the appropriate level for tests and full reporting of outcomes

Х $\square$ Estimates of effect sizes (e.g. Cohen's $d$, Pearson's $r$ ), indicating how they were calculated

Our web collection on statistics for biologists contains articles on many of the points above.

\section{Software and code}

Policy information about availability of computer code

Data collection We used "Data Browser" from "World Energy Balances 2020" (IEA) to access data on electricity generation. We used "World Development Indicators DataBank" (WorldBank) to access aggregate summary statistics. We used "Global Coal Plant Tracker" (Global Energy Monitor) to access data on coal plant investments. We used "World Economic Outlook Database" (IMF) to access consumer price indices.

Data analysis For our analysis we developed scripts in Python and R, which can be accessed through https://github.com/Imissbach/DIDA_SI/tree/main/ Code.

For manuscripts utilizing custom algorithms or software that are central to the research but not yet described in published literature, software must be made available to editors and reviewers. We strongly encourage code deposition in a community repository (e.g. GitHub). See the Nature Research guidelines for submitting code \& software for further information.

\section{Data}

Policy information about availability of data

All manuscripts must include a data availability statement. This statement should provide the following information, where applicable:

- Accession codes, unique identifiers, or web links for publicly available datasets

- A list of figures that have associated raw data

- A description of any restrictions on data availability

Microdata from household surveys are available upon request from related statistical offices. Note that restrictions and fees apply. Country-specific trade and emissions data are available from GTAP10 (https://www.gtap.agecon.purdue.edu/default.asp) subject to fees. Both, microdata from household surveys and GTAP are available from the authors upon reasonable request and conditional on approval by the responsible statistical offices or GTAP respectively. Aggregate data on the household level can be accessed via https://github.com/Imissbach/DIDA_SI. Data on electricity generation is accessible by IEA's World Energy Balances 2020 Data Browser (https://www.iea.org/data-and-statistics). Aggregate summary statistics on single countries are available in the WorldBank's World Development 


\section{Field-specific reporting}

Please select the one below that is the best fit for your research. If you are not sure, read the appropriate sections before making your selection.

Life sciences

Behavioural \& social sciences

Ecological, evolutionary \& environmental sciences

For a reference copy of the document with all sections, see nature.com/documents/nr-reporting-summary-flat.pdf

\section{Ecological, evolutionary \& environmental sciences study design}

All studies must disclose on these points even when the disclosure is negative.

Study description

Research sample

Sampling strategy

Data collection

Timing and spatial scale

Data exclusions

Reproducibility

Randomization

Blinding

Did the study involve field work? $\square$ Yes $\quad$ No across eight Asian countries.

N/A

This study is non-experimental. not necessary.

We match input-output data with microdata from household to surveys to evaluate the distributional implications of carbon pricing

We draw on data from household budget surveys, which were collected by national statistical offices and are nationally representative for each country in this study. Note that questionnaires and sampling strategies differ between countries.

Data from household budget surveys was collected by national statistical offices. We collected and harmonised data from Bangladesh (Household Income and Expenditure Survey 2010), India (National Sample Survey 2012), Indonesia (Survei Sosial Ekonomi Nasional 2018), Pakistan (Household Integrated Income and Consumption Survey 2015), Philippines (Family Income and Expenditure Survey 2015), Thailand (Household Socio-Economic Survey 2013), Turkey (Household Budget Survey 2013) and Vietnam (Vietnam Household Living Standard Survey 2012). Data on national and international trade relations and emissions were collected from the Global Trade Analysis Project (GTAP) using database 10. We use data on coal fire plants from Global Energy Monitor, on aggregate country statistics and exchange rates by WorldBank and on consumer price indices from IMF.

Bangladesh, India, Indonesia, Pakistan, Philippines, Thailand, Turkey, Vietnam.

We winsorize expenditure data for each country at the household and item level to detect outliers. Beside, no data is excluded.

Code for reproducibility can be accessed via https://github.com/Imissbach/DIDA_SI. Code for transformation of raw data will be provided upon reasonable request from the authors.

Household data was collected by respective statistical offices with the purpose of identifying living and consumption standards of their population. In our non-experimental design we use this data to model additional costs from carbon pricing. Blinding is hence

\section{Reporting for specific materials, systems and methods}

We require information from authors about some types of materials, experimental systems and methods used in many studies. Here, indicate whether each material, system or method listed is relevant to your study. If you are not sure if a list item applies to your research, read the appropriate section before selecting a response.

Materials \& experimental systems

n/a Involved in the study

\ $\square$ Antibodies

\ $\square$ Eukaryotic cell lines

\ $\square$ Palaeontology and archaeology

$\bigotimes \square$ Animals and other organisms

$\bigotimes \square$ Human research participants

\ $\square$ Clinical data

$\bigotimes \mid \square$ Dual use research of concern

\author{
Methods \\ $\mathrm{n} / \mathrm{a}$ Involved in the study \\ \ $\square$ ChIP-seq \\ Х $\square$ Flow cytometry \\ $\bigotimes \square$ MRI-based neuroimaging
}

